\title{
DAMPAK PENAMBAHAN ZAT ADITIF C20 TERHADAP KINERJA MESIN YAMAHA SE88
}

\author{
MUH. DARWIS ${ }^{1}$, RAMLI ${ }^{2}$, HASNI KASIM ${ }^{3}$ \\ Pengajar Program Studi Teknik Mesin ${ }^{1,2}$ Dan Program Studi Teknik Pertambangan ${ }^{3}$ \\ Universitas Pejuang Republik Indonesia- Makassar \\ Email : muhdarwis41@gmail.com ${ }^{1}$,ramli@gmail.com ${ }^{2}$, hasnikasim14@gmail.com ${ }^{3}$
}

\begin{abstract}
ABSTRAK
Motor bensin merupakan motor pembakaran dalam dimana tenaga yang digunakan untuk menggerakkan motor diperoleh dari pembakaran bahan bakar yang terjadi didalam motor itu sendiri, sehingga gas pembakaran yang terjadi sekaligus berfungsi sebagai fluida kerja. Kemajuan teknologi otomotif termasuk pada sistem pembakaran kompresi tinggi memerlukan jenis bahan bakar yang sesuai agar pembakaran berjalan dengan sempurna. Hal ini dapat dipenuhi dengan menggunakan zat aditif C20 untuk meningkatkan kinerja mesin. Penelitian ini membandingkan pemakaian bahan bakar bensin murni dengan bensin campuran zat aditif C20 dengan variasi putaran mesin 2000- rpm sampai 4000-rpm dengan step putaran 500-rpm serta beban $25 \mathrm{~kg}$. kinerja mesin yang diteliti adalah: Torsi, Daya, Konsumsi Bahan Bakar, Efisiensi Volumetrik dan Efisiensi Termal. Dari hasil pengujian dan analisa didapatkan bahwa Konsumsi bahan bakar spesifik (Sfc) campuran [C20] lebih rendah dibandingkan bila mesin menggunakan bensin murni sedangkan Efisiensi volumetrik dan Efisiensi termal mesin yang menggunakan zat aditif $\mathrm{C} 20$ lebih besar dibandingkan dengan bila mesin menggunakan bensin murni.
\end{abstract}

Kata kunci: Zat adhitif C20, kinerja mesin

\begin{abstract}
Gasoline motor is an internal combustion motor where the power used to drive the motor is obtained from the combustion of fuel that occurs inside the motor itself, so that the combustion gases that occur simultaneously function as a working fluid. Advances in automotive technology, including high compression combustion systems, require the right type of fuel for complete combustion. This can be met by using $\mathrm{C} 20$ additives to improve engine performance. This study compares the use of pure gasoline fuel with a mixture of gasoline additives $\mathrm{C} 20$ with engine speed variations of 2000-rpm to 4000-rpm with a 500-rpm rotation step and a load of 25 $\mathrm{kg}$. engine performance under study are: Torque, Power, Fuel Consumption, Volumetric Efficiency and Thermal Efficiency. From the results of testing and analysis, it is found that the specific fuel consumption (Sfc) of the mixture [C20] is lower than when the engine uses pure gasoline, while the volumetric efficiency and thermal efficiency of the engine using C20 additives is greater than when the engine uses pure gasoline.
\end{abstract}

Keywords: C20 additive, engine performance

\section{PENDAHULUAN}

Kemajuan teknologi otomotif memicu perkembangan teknologi kendaraan yang semakin berkembang, termasuk pada sistem pembakaran dimana diperlukan kompresi tinggi sehingga memerlukan jenis bahan bakar yang sesuai agar pembakaran tersebut berjalan dengan sempurna. Proses pembakaran kurang sempurna akan mengakibatkan daya yang dihasilkan mesin kurang optimal, produksi polutan gas buang sangat tinggi dan akan memboroskan konsumsi bahan bakar minyak (BBM) (Arismunandar W, 1988). Proses pembakaran sangat berpengaruh terhadap prestasi kerja mesin dan kadar gas buang yang dihasilkan.

Salah satu faktor penunjang untuk meningkatkan efesiensi dan efektivitas dari mesin adalah pembakaran bahan bakar yang baik dan untuk mewujudkan proses pembakaran bahan bakar yang baik dan efesien yaitu dengan meningkatkan kualitas bahan bakar yakni dengan menambahkan zat adhitif . 
Pada penelitian ini digunakan campuran zat aditif dengan bahan bakar bensin yang bertujuan untuk meningkatkan performansi mesin otto melalui kualitas proses pembakaran sehingga pembakaran dapat berlangsung secara sempurna.

Berdasarkan latar belakang maka perumusan masalahnya adalah seberapa besar dampak penambahan zat aditif C20 terhadap kinerja mesin Yamaha SE88. Adapun tujuan dari penelitian ini adalah untuk mengetahui besarnya dampak penambahan zat aditif C20 terhadap kinerja mesin Yamaha SE88.

Adapun batasan masalah dalam penelitian ini adalah sebagai berikut:

1. Mesin uji yaitu Mesin Yamaha SE88.

2. Zat aditif yang digunakan bermerek Jet Age Conditioner (JAC).

3. Bahan pengujian adalah bahan bakar bensin dan campuran bensin dengan zat aditif dengan komposisi $4900 \mathrm{ml}$ bensin dicampur $100 \mathrm{ml}$ zat aditif [20\%,C20].

4. Kinerja mesin yang diteliti adalah: Torsi, Daya, Konsumsi Bahan Bakar, Efisiensi Volumetrik dan Efisiensi Termal.

5. Variasi putaran mesin dan beban yang meliputi variasi putaran mesin 2000- rpm sampai 4000-rpm dengan step putaran 500-rpm serta beban $25 \mathrm{~kg}$.

Manfaat dari penelitian adalah untuk mengetahui jenis bahan bakar yang sesuai agar kinerja mesin lebih maksimal.

\section{METODE PENELITIAN}

Bahan yang menjadi objek pengujian ini adalah bahan bakar bensin dan campuran bensin dengan zat aditif dengan komposisi $4900 \mathrm{ml}$ bensin dicampur $100 \mathrm{ml}$ zat aditif [20\%,C20]. Zat aditif yang digunakan bermerek Jet Age Conditioner (JAC)

\section{A. Alat}

Alat uji yang digunakan dalam eksperimental ini terdiri dari :

1. Mesin Yamaha SE88

2. Bom kalorimeter untuk mengukur nilai kalor bahan bakar.

\section{B. Pelaksanaan Pengujian}

Pengujian Performansi Mesin Yamaha SE88, Pengujian dilakukan untuk pemakaian bahan bakar campuran(C20) dan bensin murni dengan volume uji sebanyak $50 \mathrm{ml}$. Pada pengujian ini dilakukan variasi putaran mesin dan beban yang meliputi variasi putaran mesin 2000- rpm sampai 4000-rpm dengan step putaran 500-rpm serta beban $25 \mathrm{~kg}$.

\section{Teknik Pengumpulan Data}

Data yang dipergunakan dalam pengujian ini meliputi :

1. Data primer, merupakan data yang diperoleh langsung dari pengukuran dan pembacaan pada unit instrumentasi dan alat ukur pada masing-masing pengujian.

2. Data sekunder, merupakan data yang diperoleh dari spesifikasi bahan aditif yang digunakan dan data karakteristik bahan bakar bensin dari PT. Pertamina.

\section{Pengolahan Data}

Data yang diperoleh dari data primer dan data sekunder diolah ke dalam persamaan, kemudian data hasil perhitungan disajikan dalam bentuk grafik dan dianalisa.

\section{HASIL DAN PEMBAHASAN}

\section{Hasil}

\section{A. Pengujian Performansi Mesin Yamaha SE88}

1. Torsi

Torsi mengalami peningkatan seiring dengan peningkatan putaran mesin dan pertambahan beban. 
Vol 2. No. 1, Januari 2022 P-ISSN : 2774-8030, e-ISSN : 2774-8030

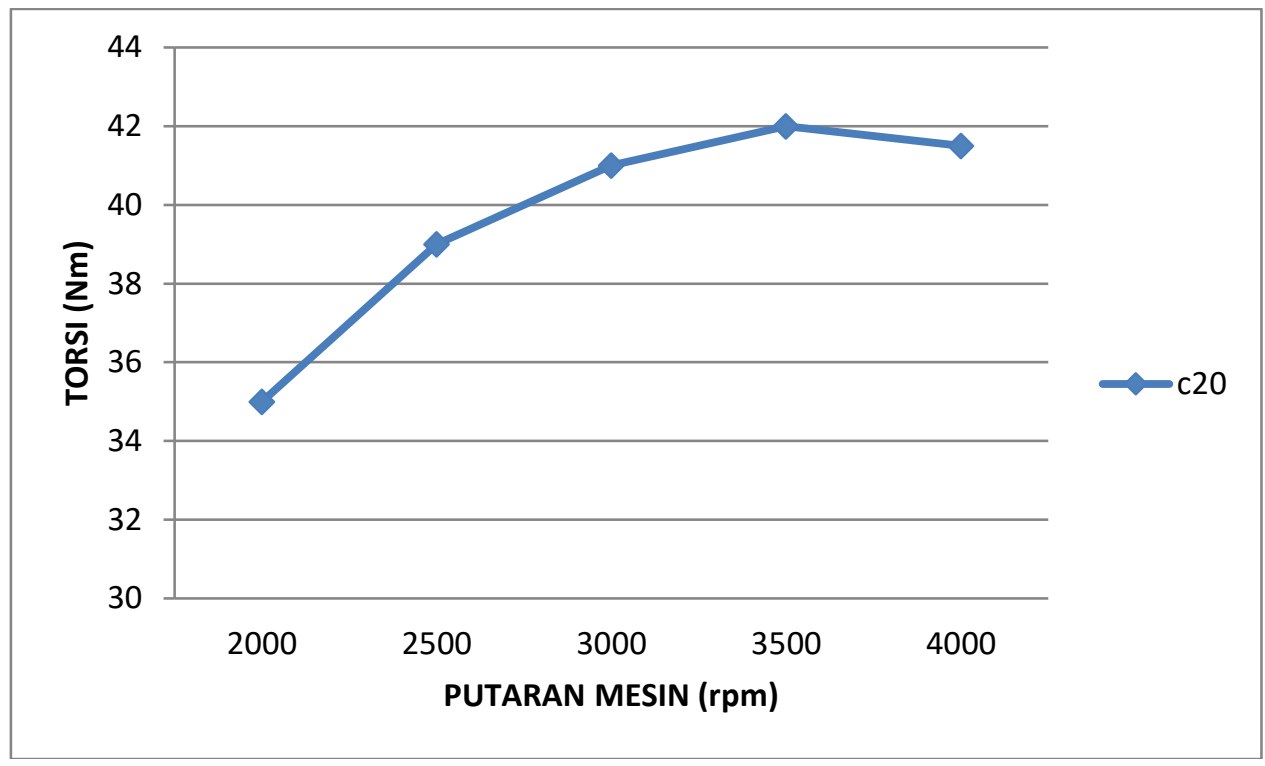

Gambar 1. Grafik Torsi vs Putaran Mesin dengan beban $25 \mathrm{~kg}$

\section{Daya}

Besarnya daya yang dihasilkan mesin dipengaruhi oleh putaran poros engkol yang terjadi akibat dorongan piston yang dihasilkan karena adanya pembakaran bahan bakar dengan udara. Jika konsumsi bahan bakar dan udara diperbesar maka akan semakin besar juga daya yang dihasilkan mesin. Semakin cepat poros engkol berputar maka akan semakin besar daya yang dihasilkan.

\section{Konsumsi Bahan Bakar}

Konsumsi bahan bakar spesifik dipengaruhi oleh putaran mesin. Semakin tinggi putaran mesin maka konsumsi bahan bakar juga meningkat dan sebaliknya. Hal ini disebabkan oleh peningkatan laju aliran bahan bakar.

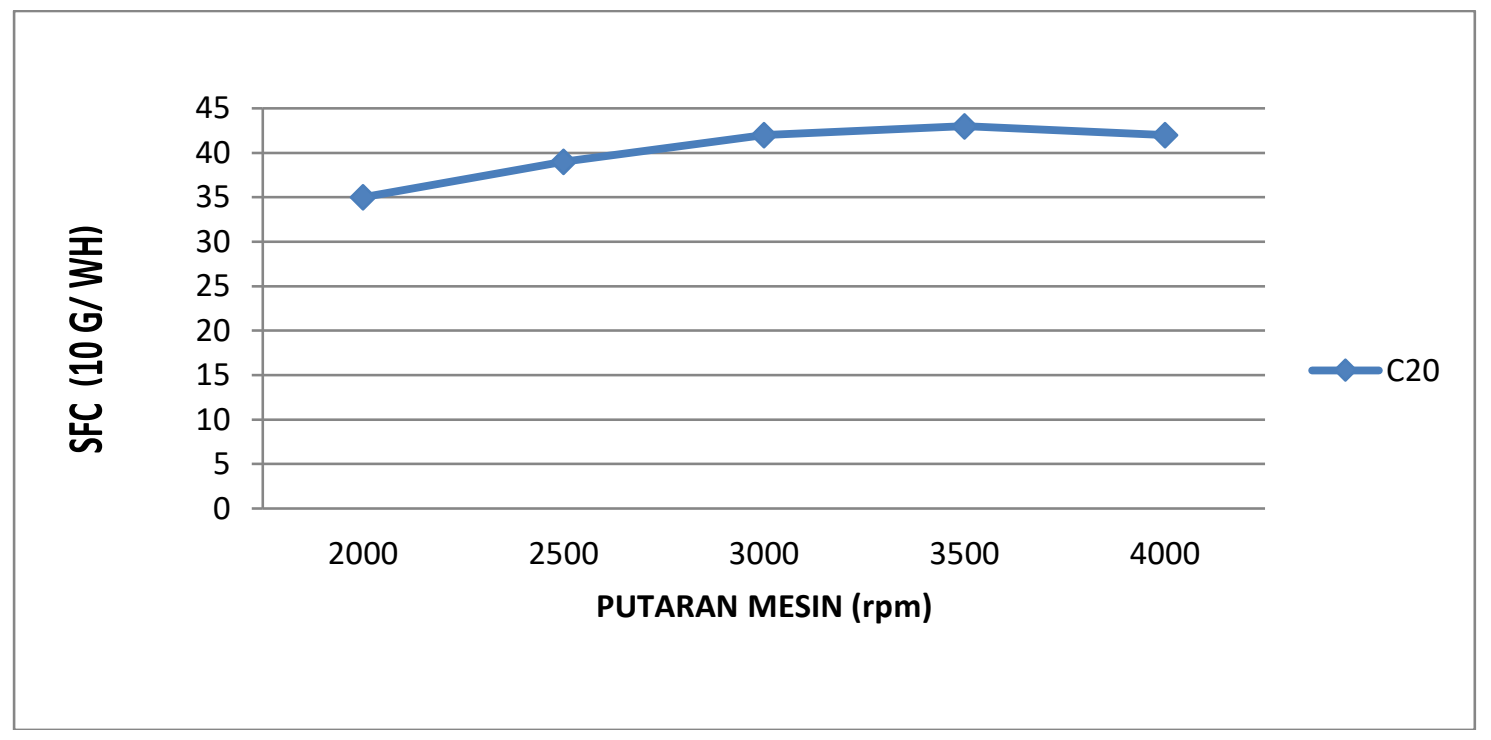

Gambar 2. Grafik Sfc vs putaran mesin dengan beban $25 \mathrm{~kg}$

\section{Efisiensi Volumetrik}

Efisiensi volumetrik menunjukkan perbandingan antara jumlah udara yang terisap sebenarnya terhadap jumlah udara yang terisap sebanyak volume langkah torak untuk setiap langkah isap. Efisiensi volumetrik sangat dipengaruhi oleh putaran mesin. 


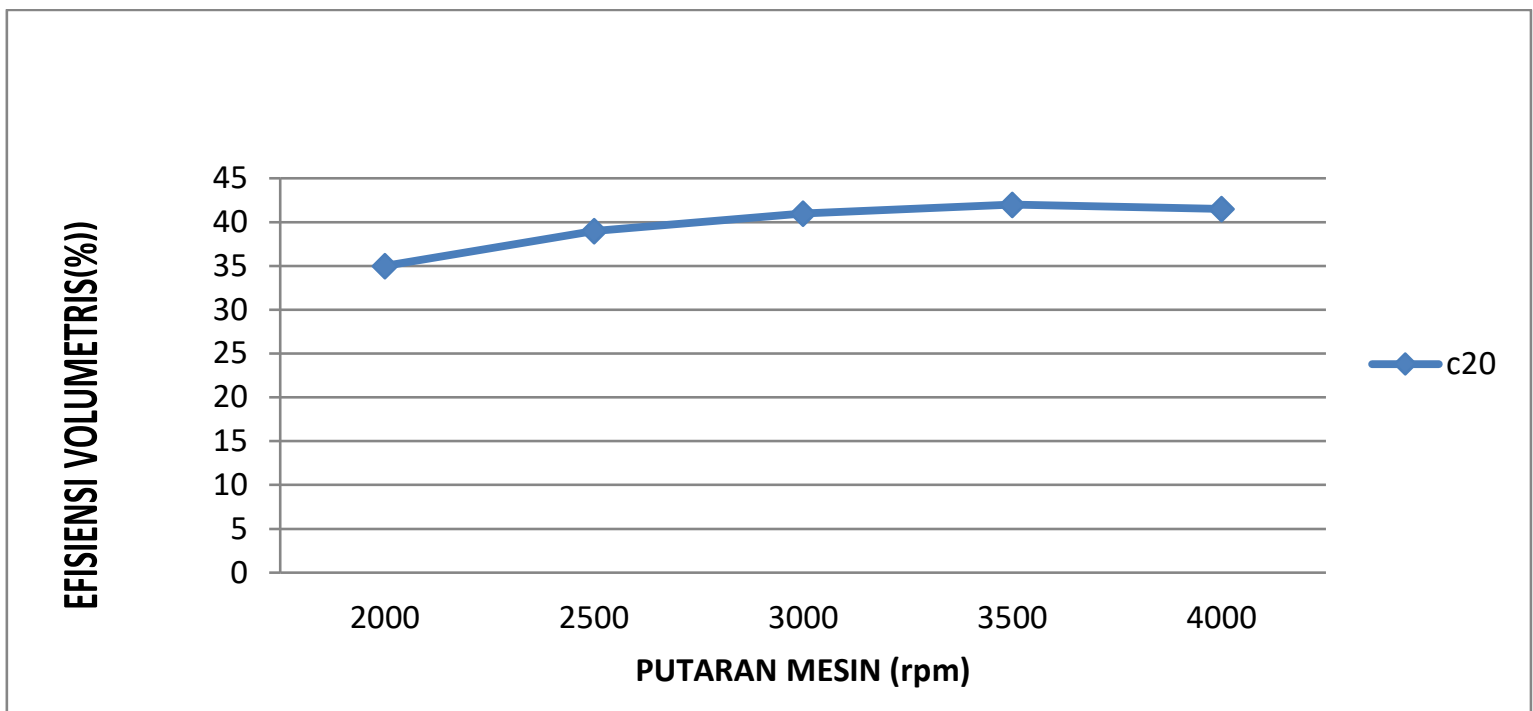

Gambar 3. Grafik efisiensi volumetrik vs putaran mesin dengan beban 25 kg

\section{Efisiensi Termal}

Kenaikan putaran poros pada beban konstan cenderung mengurangi efisiensi termal, untuk beban konstan daya efektif yang dihasilkan relatif konstan dan kenaikan putaran poros akan mempersingkat waktu proses pencampuran bahan bakar-udara, sehingga pembakaran berlangsung kurang baik, hal ini akan menghasilkan energi pembakaran yang lebih kecil dan cenderung mengurangi efisiensi termal. Pada kondisi penambahan beban pada putaran poros konstan akan terjadi penambahan kandungan oksigen yang terikat pada campuran antara zat aditif dengan bensin sebanding dengan penambahan massa bahan bakar, hal ini akan menyebabkan semakin banyak bahan bakar yang terbakar dan daya efektif yang lebih besar, sehingga meningkatkan efisiensi termal.

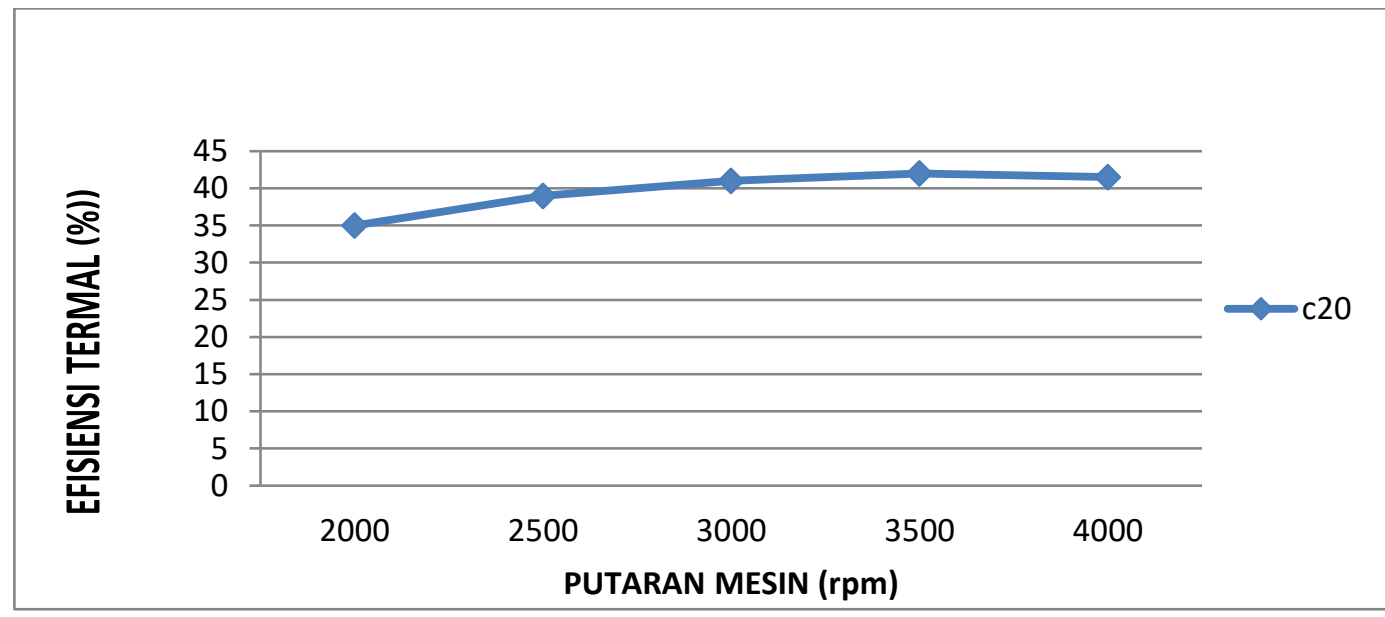

Gambar 4. Grafik efisiensi termal vs putaran mesin dengan beban $25 \mathrm{~kg}$

\section{Pembahasan}

\section{Torsi dan Daya}

Gaya tekan putar pada bagian yang berputar disebut torsi, sepeda motor digerakkan oleh torsi dari crankshaft (Jama dan Wagino, 2008: 23). Torsi adalah ukuran kemampuan mesin untuk melakukan kerja. Besaran torsi adalah besaran turunan yang biasa digunakan untuk menghitung energi yang dihasilkan dari benda yang berputar pada porosnya (Raharjo dan Karnowo, 2008: 98). Torsi yang dihasilkan suatu mesin dapat diukur dengan menggunakan dynamometer yang dikopel dengan poros output mesin.

Daya adalah besarnya kerja motor persatuan waktu (Arends dan Berenschot, 1980: 18). Daya yang dihasilkan poros output ini memiliki persamaan (Heywood, 1988: 46): 


$$
P_{B}=\frac{2 . \pi \cdot n}{60} T
$$

dimana

$P_{B}=$ Daya $($ Watt $)$

$n=$ Putaran mesin (rpm)

$T=$ Torsi (N.m)

Berdasarkan grafik pada gambar 1, torsi mengalami peningkatan seiring dengan peningkatan putaran mesin dan pertambahan beban. Besarnya daya yang dihasilkan mesin dipengaruhi oleh putaran poros engkol yang terjadi akibat dorongan piston yang dihasilkan karena adanya pembakaran bahan bakar dengan udara. Jika konsumsi bahan bakar dan udara diperbesar maka akan semakin besar juga daya yang dihasilkan mesin. Semakin cepat poros engkol berputar maka akan semakin besar daya yang dihasilkan.

\section{Konsumsi Bahan Bakar Spesifik}

Konsumsi bahan bakar adalah jumlah bahan bakar per waktunya untuk menghasilkan daya sebesar 1 HP. Jadi konsumsi bahan bakar adalah ukuran ekonomi pemakaian bahan bakar (Raharjo dan Karnowo, 2008: 115). Konsumsi bahan bakar spesifik (specific fuel consumption, $s f c$ ) adalah parameter unjuk kerja mesin yang berhubungan langsung dengan nilai ekonomis sebuah mesin (Heywood, 1988:51), maka :

$$
\text { Sfc }=\frac{m_{f} \times 10^{3}}{P_{B}}
$$

dimana :

$\mathrm{Sfc}=$ konsumsi bahan bakar spesifik (g/kW.h).

$m_{f}=$ laju aliran bahan bakar(kg/jam).

Besarnya laju aliran massa bahan bakar $m_{f}=$ dihitung dengan persamaan berikut:

$$
m_{f}=\frac{s g_{f} \cdot V_{f} \cdot 10^{-3}}{t_{f}} \times 3600
$$

dimana :

$S g_{f}=$ spesific gravity

$V_{f}=$ volume bahan bakar yang diuji (dalam hal ini $50 \mathrm{ml}$ ).

$t_{f}=$ waktu untuk menghabiskan bahan bakar sebanyak volume uji (detik).

Berdasarkan grafik pada gambar 2, konsumsi bahan bakar spesifik dipengaruhi oleh putaran mesin. Semakin tinggi putaran mesin maka konsumsi bahan bakar juga meningkat dan sebaliknya. Hal ini disebabkan oleh peningkatan laju aliran bahan bakar.

\section{Efisiensi Volumetrik}

Efisiensi volumetrik $\left(\eta_{v}\right)$ (Heywood, 1988:52). dirumuskan dengan persamaan berikut

$$
\eta_{\mathrm{v}}=\frac{\text { Berat udara segar yang terisap }}{\text { Berat udara sebanyak volume langkah torak }}
$$

Berat udara segar yang terisap

$$
=\frac{m_{a}}{60} \cdot \frac{2}{n}
$$


Massa ideal udara per siklus

$\mathrm{m}_{\mathrm{a}}=\rho_{a} \cdot V_{s}$

Dimana

$\rho_{a}=$ massa jenis udara dan

$\mathrm{Vs}=$ volume suction .

Dengan mensubstitusikan persamaan diatas, maka diperoleh efisiensi volumetrik :

$$
\eta_{v}=\frac{2 . m_{a}}{60 . n} \cdot \frac{1}{\rho_{a} \cdot V_{s}}
$$

Berdasarkan grafik pada gambar 3, efisiensi volumetrik menunjukkan perbandingan antara jumlah udara yang terisap sebenarnya terhadap jumlah udara yang terisap sebanyak volume langkah torak untuk setiap langkah isap. Efisiensi volumetrik sangat dipengaruhi oleh putaran mesin.

\section{Efisiensi Termal}

Kerja berguna yang dihasilkan selalu lebih kecil dari pada energi yang dibangkitkan piston karena sejumlah energi hilang akibat adanya rugi-rugi mekanis (mechanical losses). Dengan alasan ekonomis perlu dicari kerja maksimum yang dapat dihasilkan dari pembakaran sejumlah bahan bakar. Efisiensi ini disebut sebagai efisiensi termal (brake thermal efficiency, $\left.\eta_{b}\right)$ :

$$
\eta_{b}=\frac{\text { Daya keluaran aktual }}{\text { Laju panas yang masuk }}
$$

Laju panas yang masuk Q, dapat dihitung dengan rumus berikut :

$$
Q=m_{f} \cdot \text { LHV }
$$

dimana LHV = nilai kalor bawah bahan bakar $(\mathrm{kJ} / \mathrm{kg})$

Jika daya keluaran ( $B P$ ) dalam satuan $\mathrm{kW}$, laju aliran bahan bakar $m_{f}$ dalam satuan $\mathrm{kg} / \mathrm{jam}$, maka :

$$
\eta_{b}=\frac{P_{B}}{m_{f} \cdot L H V} \cdot 3600
$$

Berdasarkan grafik pada gambar 4, kenaikan putaran poros pada beban konstan cenderung mengurangi efisiensi termal, untuk beban konstan daya efektif yang dihasilkan relatif konstan dan kenaikan putaran poros akan mempersingkat waktu proses pencampuran bahan bakar-udara, sehingga pembakaran berlangsung kurang baik, hal ini akan menghasilkan energi pembakaran yang lebih kecil dan cenderung mengurangi efisiensi termal. Pada kondisi penambahan beban pada putaran poros konstan akan terjadi penambahan kandungan oksigen yang terikat pada campuran antara zat aditif dengan bensin sebanding dengan penambahan massa bahan bakar, hal ini akan menyebabkan semakin banyak bahan bakar yang terbakar dan daya efektif yang lebih besar, sehingga meningkatkan efisiensi termal.

Berdasarkan penelitian Wahyudi dkk (2012) mengatakan bahwa dengan penambahan zat aditif akan memperbaiki proses pembakaran pada mesin kendaraan bermotor.

\section{KESIMPULAN}

Hasil pengujian menunjukkan bahwa :

1. Konsumsi bahan bakar spesifik (Sfc) campuran [C20] lebih rendah dibandingkan bila mesin menggunakan bensin murni.. 
2. Efisiensi volumetrik campuran [C20] lebih besar dibandingkan bila mesin menggunakan bensin murni.

3. Efisiensi termal mesin yang menggunakan zat aditif C20 lebih besar dibandingkan dengan bensin murni.

\section{DAFTAR PUSTAKA}

Arends.BPM dan Berenschot.H. (1980). Motor Bensin. Jakarta: Erlangga.

Arismunandar, Wiranto. (1988). Penggerak Mula Motor Bakar Torak. Bandung : Penerbit ITB Bandung.

Heywood, John B, (1988). Internal Combustion Engine Fundamental. Singapore : Mc Graw Hill Book Company.

Jama, Jalius dan Wagino. (2008) Teknik Sepeda Motor Jilid 1. Jakarta: Direktorat Pembinaan Sekolah Menengah Kejuruan, Direktorat Jenderal Manajemen Pendidikan Dasar dan Menengah, Departemen Pendidikan Nasional.

Raharjo, Winarno Dwi dan Karnowo. (2008). Mesin Konversi Energi. Semarang: Universitas Negeri Semarang.

Wahyudi, dkk. (2012). Analisis Penggunaan Zat Aditif pada Bahan bakar Terhadap Emisi Gas Buang pada Mesin Sepeda Motor Yamaha. Jurnal PROTON, Vol. 4 No. 2, Halaman 10-15. http://doi.org/10.31328/jp.v4i2.335 